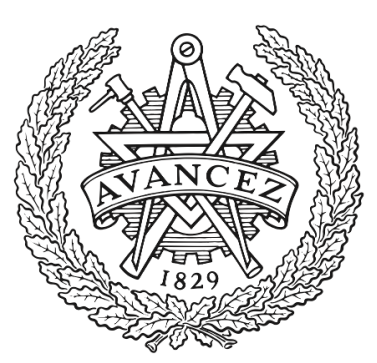

CHALMERS

\title{
Cost-optimal energy management of hybrid electric vehicles using fuel cell/battery health-aware predictive control
}

Downloaded from: https://research.chalmers.se, 2023-04-26 13:23 UTC

Citation for the original published paper (version of record):

Hu, X., Zou, C., Tang, X. et al (2020). Cost-optimal energy management of hybrid electric vehicles using fuel cell/battery health-aware predictive control. IEEE Transactions on Power Electronics, 35(1): 382-392.

http://dx.doi.org/10.1109/TPEL.2019.2915675

N.B. When citing this work, cite the original published paper.

(C)2020 IEEE. Personal use of this material is permitted.

However, permission to reprint/republish this material for advertising or promotional purposes 


\title{
Cost-optimal energy management of hybrid electric vehicles using fuel cell/battery health-aware predictive control
}

\author{
Xiaosong Hu, Senior Member, IEEE, Changfu Zou, Member, IEEE, Xiaolin Tang, \\ Teng Liu, Member, IEEE, Lin $\mathrm{Hu}$
}

\begin{abstract}
Energy management is an enabling technology for increasing the economy of fuel cell/battery hybrid electric vehicles. Existing efforts mostly focus on optimization of a certain control objective (e.g., hydrogen consumption), without sufficiently considering the implications for on-board power sources degradation. To address this deficiency, this article proposes a cost-optimal, predictive energy management strategy, with an explicit consciousness of degradation of both fuel cell and battery systems. Specifically, we contribute two main points to the relevant literature, with the purpose of distinguishing our study from existing ones. First, a model predictive control framework, for the first time, is established to minimize the total running cost of a fuel cell/battery hybrid electric bus, inclusive of hydrogen cost and costs caused by fuel cell and battery degradation. The efficacy of this framework is evaluated, accounting for various sizes of prediction horizon and prediction uncertainties. Second, the effects of driving and pricing scenarios on the optimized vehicular economy are explored.
\end{abstract}

Index Terms-Batteries, energy management, fuel cell, hybrid electric vehicle, predictive control, sustainable transport

\section{INTRODUCTION}

\section{A. Motivation and Challenges}

Increasingly severe fuel consumption and environmental pollution have been strongly pushing the academia and automotive sector to actively develop and deploy fuel cell hybrid electric vehicles (FCHEVs) [1]-[4]. FCHEVs diversify energy sources of mobility, enabling a good synergy of transportation and renewables [5]. The fuel cell-battery-motor coupling featured by FCHEVs is, however, quite complicated and directly influences overall vehicular performance [6], constituting the

Manuscript received January 17, 2019; revised March 30, 2019; accepted May 03, 2019. This work was supported in part by the EU-funded Marie Sklodowska-Curie Individual Fellowships (IF) Project under Grant 706253 pPHEV-H2020-MSCA-IF-2015. The work of L. Hu was supported by the National Natural Science Foundation of China project under Grant 51875049. (Corresponding authors: Changfu Zou and Xiaolin Tang.)

X. Hu, X. Tang, and T. Liu are with the State Key Laboratory for Mechanical Transmission, Department of Automotive Engineering, Chongqing University, Chongqing 400044, China. X. Hu is also with the Advanced Vehicle Engineering Centre, Cranfield University, Cranfield, MK43 0AL, UK. T. Liu is also with the Mechanical and Mechatronics Engineering Department, University of Waterloo, N2L 3G1, Canada (xiaosonghu@ieee.org, tangx10923@cqu.edu.cn, tengliu17@gmail.com).

C. Zou is with the Department of Electrical Engineering, Chalmers University of Technology, Gothenburg 41296, Sweden (changfu.zou@chalmers.se).

$\mathrm{L}$. Hu is with the School of Automotive and Mechanical Engineering, Changsha University of Science and Technology, Changsha 410205, China (hulin888@ sohu.com). first challenge for system-level energy management. Unlike internal combustion engines (ICEs), the lifetime of the two electrochemical power sources (fuel cell and battery systems) is highly vulnerable to their operating conditions. This causes another challenge of how to coordinate the two energy units such that the vehicular total cost of ownership can be reduced. To address the two main challenges, we propose a look-ahead health-conscious energy management strategy to maximize the economy of an FCHEV.

\section{B. Literature Review}

Energy management of FCHEVs and ICE-included hybrid electric vehicles (HEVs) is certainly a vast field of research [7]-[9]. A large number of strategies have been proposed in the literature, which can be roughly divided into two categories, i.e., rule-based and optimization-based approaches. Each type has its own advantages and disadvantages.

Rule-based energy management is centered on heuristic rules governing the vehicle operating modes [10]. These rules are invariably derived from engineering experiences, as simple functions of battery and/or engine states. For example, when the battery State-of-Charge (SOC) exceeds a higher bound, the pure electric mode is adopted; when the battery SOC is lower than a lower bound, the ICE mode is operated. Common rule-based power management strategies include thermostat control [11], fuzzy logic [12], etc. Salient upsides of this type of method are simplicity, ease of real-time implementation, and strong resilience against driving patterns. For these reasons, rule-based methods are predominantly being used in HEVs in the current market. Nonetheless, the effects of these rules are typically far away from the optimality of vehicle design/control objectives, incenting alternatives to seek noticeable improvements.

Optimization-based energy management strategies have been actively developed in order to achieve better vehicular performance [9]. The overarching goal of this type of method is to optimize a predefined criterion, like fuel consumption, subject to a set of operational constraints, given a hybrid powertrain model [13]. Sometimes, multiple objectives are considered to investigate tradeoffs of different concerns [14][16]. As a globally optimal benchmark, dynamic programming (DP) was often exploited to develop a theoretically optimum energy management strategy and evaluate other algorithms 
[17], [18]. For instance, the operational cost of a fuel cell hybrid electric vehicle was minimized by DP in [19]. The computational efficiency of DP is, however, very low, especially for dynamic models with multiple states. Another global optimization method, convex programming $(\mathrm{CP})$, was also leveraged to synthesize HEVs energy management strategies [14], [20]-[22]. Due to the convexity, CP can guarantee a globally optimal solution with exceptionally fast calculation. The model simplification and convexification somewhat degrade the optimality, in contrast to DP. Typically, noncausal DP and CP can only be implemented offline, as driving cycles must be known beforehand. To explore the possibility of online optimized energy management, causal optimization methods, e.g., equivalent consumption minimization strategy (ECMS) [23], [24], Pontryagin's Minimum Principle (PMP) [25], [26], and model predictive control (MPC) [27], [28], were adopted. These controllers with appropriate design and tuning always produce a satisfactory performance in energy consumption, operating cost, or the total cost of vehicle ownership.

A vast majority of existing studies on FCHEVs energy management merely consider how to minimize hydrogen consumption, without involving performance degradation of fuel cell/energy storage systems. The economy potential of FCHEVs is insufficiently assessed. A few papers attempted to establish power management strategies cognizant of the tradeoff between fuel cell health and hydrogen economy. For example, fuel efficiency, cost, and life-cycle carbon emissions of an FCHEV were optimized via the genetic algorithm in [29]. Fuel cell lifetime was governed by imposing constraints on fuel cell output power in ECMS [30], PMP [31], and CP [14] energy management controllers. A stochastic DP controller to minimize the summation of hydrogen and fuel cell costs was introduced in [32], [33] as well. However, these studies did not take energy storage degradation into consideration. A battery health-aware power management strategy of an FCHEV equipped with hybrid energy storage was constructed via $\mathrm{CP}$ in [34], where the impact of fuel cell health was neglected. Xu et al. [35] incorporated both fuel cell and battery degradation models into a bi-loop framework for offline component sizing and DP-based energy management of an FCHEV. To reduce the computational burden, such a framework was modified by means of a DP-refined rule-based controller in the inner loop [36], [37].

\section{Main Contributions}

To the best knowledge of the authors, no efforts have been made to develop an FCHEV energy management strategy perceptive of the lifetime of both fuel cell and battery systems in a cost-optimal, predictive manner. In order to bridge such a research gap, this article presents two original contributions that distinguish our work from existing schemes. First, we devise an MPC framework, for the first time, to minimize the expenditure of an FCHEV, inclusive of hydrogen cost and costs associated with fuel cell and battery degradation. The performance and computational efficiency of this framework are carefully examined, considering different sizes of prediction horizon and prediction uncertainties. Second, the

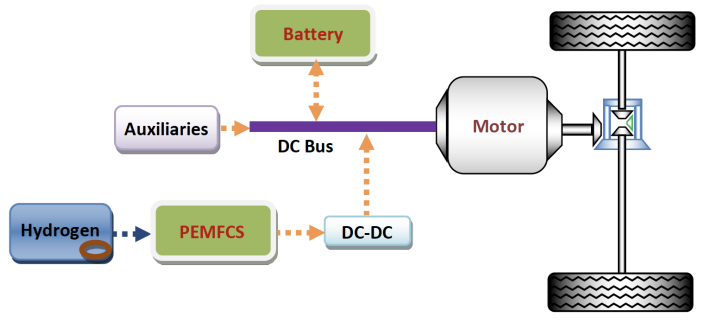

Fig. 1: Configuration of the fuel cell hybrid electric bus.

sensitivity of the health-conscious MPC power management to driving patterns and the component price is carried out, so that the effects of driving and pricing scenarios on the optimized vehicular economy can be revealed.

\section{Organization}

The rest of the paper proceeds as follows. The FCHEV powertrain model is detailed in Section [I] Section [II introduces the MPC energy management framework. The control results under various driving cycles are given in Section IV] The implication of power-source pricing is discussed in Section V] followed by conclusions summarized in Section VI.

\section{FCHEV POWERTRAIN MODEL}

Here, we consider a fuel cell hybrid bus powertrain, as sketched in Fig. 11. The widely-used quasi-static modeling method is leveraged to model the powertrain for a timeefficient, accurate simulation [38], [39].

\section{A. Configuration and Power Balance}

An electric motor drives the bus with a hybrid power source composed of a proton-exchange-membrane fuel cell system (PEMFCS) and a lithium-ion battery system. A DC-DC converter is adopted at the side of the PEMFCS to regulate its current flow into the DC bus, while the battery system is passively connected. The specifications of the principle powertrain components are listed in Table [ The overall power balance equation is described by

$$
\begin{array}{r}
T_{e m}(k) w_{e m}(k)+P_{\text {em,loss }}(k)+P_{a u}(k) \\
=P_{b a t}(k)+P_{f c s}(k) \eta_{d c}
\end{array}
$$

where $T_{e m}$ and $w_{e m}$ are the motor torque and speed, respectively; $P_{e m, l o s s}$ is the motor loss as a function of $T_{e m}$ and $w_{e m} ; P_{b a t}$ and $P_{f c s}$ are the battery terminal power and the PEMFCS output power, respectively; $\eta_{d c}$ is the averaged efficiency of the DC-DC converter; $P_{a u}$ is the power of auxiliaries that is assumed to be constant; $k$ is the time index.

\section{B. Motor Model}

A permanent magnet synchronous motor is used to propel the bus and do regenerative braking. The efficiency and loss data of the motor taken from [20] are plotted in Fig. 2. The 
TABLE I. MAIN VEHICLE PARAMETERS.

\begin{tabular}{ll}
\hline \hline Component & Specifications \\
\hline PEMFCS & A 1000-cell stack \\
& Power rating: $100 \mathrm{~kW}$ \\
Battery system & A 2000-cell pack \\
& Energy capacity: $15.18 \mathrm{kWh}$ \\
${ }^{a}$ Motor & Maximum power: $220 \mathrm{~kW}$ \\
${ }^{b}$ DC-DC converter & Maximum speed: $3000 \mathrm{rpm}$ \\
${ }^{a}$ Final drive & Averaged efficiency: $96 \%$ \\
${ }^{c}$ Vehicle & Gear ratio: 4.7 \\
& Chassis mass: $13476 \mathrm{~kg}$ \\
\hline \hline
\end{tabular}

${ }^{a}$ Adopted from [20]; ${ }^{b}$ Adopted from [14]; ${ }^{c}$ Adapted from [20].

motor torque and speed meet the vehicular power demand as follows:

$$
\begin{aligned}
w_{e m}(k) & =\frac{\lambda v(k)}{r} \\
T_{e m}(k) & =\max \left(T_{v}(k), T_{e m, \min }(k)\right)
\end{aligned}
$$

where $v, \lambda$, and $r$ are the vehicle speed, final drive gear ratio, and wheel radius, respectively; $T_{e m, \min }$ is the minimum negative torque during regenerative braking; $T_{v}$ is the torque request on the shaft between the motor and the final drive, which can be readily derived by the vehicular longitudinal dynamics (the derivation is detailed in Appendix of [22]). In this study, the motor is sized enough to satisfy the propelling torque request of the bus. When the braking torque request exceeds $T_{e m, \min }$, the conventional frictional braking is activated as a supplement.

\section{PEMFCS Model}

1) Hydrogen Consumption Model: We herein consider a 1000-cell PEMFCS with a power rating of $100 \mathrm{~kW}$ for an electric bus, same as the fuel cell system used in [40], whose configuration is sketched in Fig. 3. Its main elements include a fuel cell stack and four auxiliary subsystems, i.e., hydrogen circuit, air circuit, water circuit, and coolant circuit [14], [22]. These auxiliaries consume a portion of the electricity generated by the stack to ensure a normal operation of the PEMFCS. A detailed description about how these subsystems work can be found in [41]. The quasi-static hydrogen consumption model, characterizing the relationship between the hydrogen power $P_{h}$ and the PEMFCS output power $P_{f c s}$, is a scaled version of FC_ANL50H2 in ADVISOR [42], as indicated in Fig. 4

2) Health Model: Performance degradation is an entrenched issue in electrochemical power sources. How to model the PEMFCS health evolution plays an important role in the economy-targeted power management of the bus. As recognized in electrochemistry community, a multitude of tangible and intangible factors impact membrane electrode assembly (MEA) degradation, resulting in a great challenge of establishing such a model. As introduced in [33], MEA performance degradation mainly originates from the following aspects.

a) Catalyst layer degradation [33]: electrochemical active surface area (ECASA) reduction occurs, owing to agglomeration, sintering together, and detachment of platinum particles
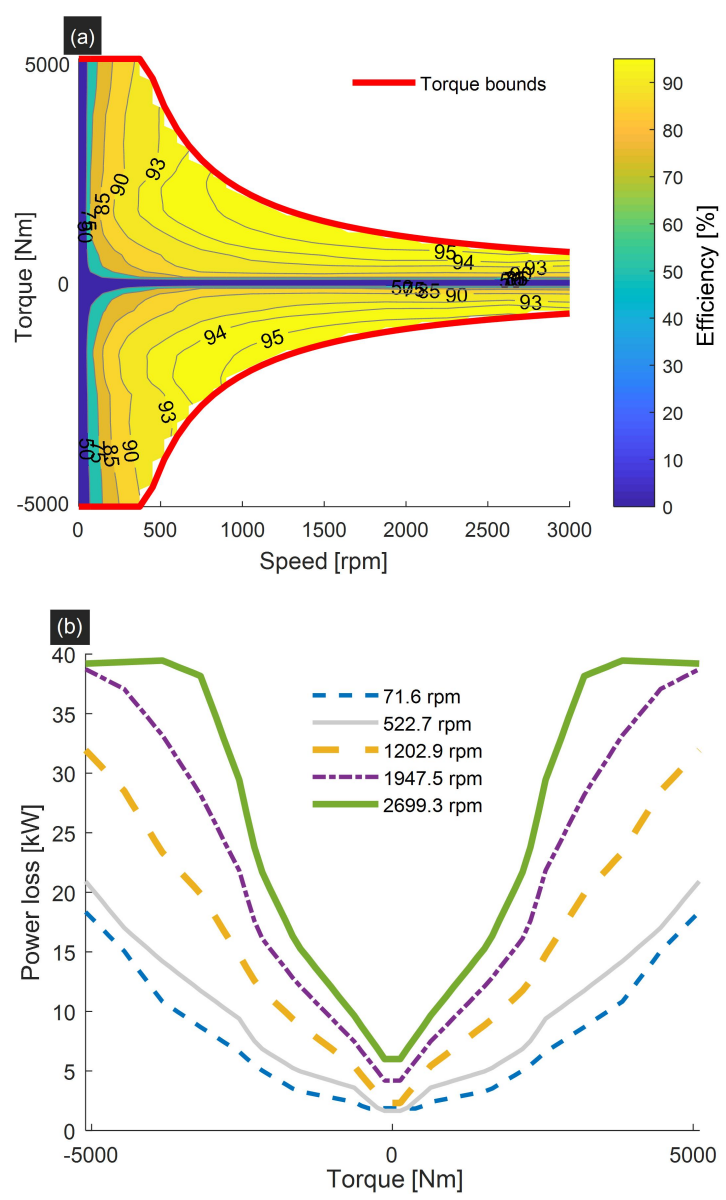

Fig. 2: (a) Motor efficiency map and (b) motor losses at exemplary speeds.

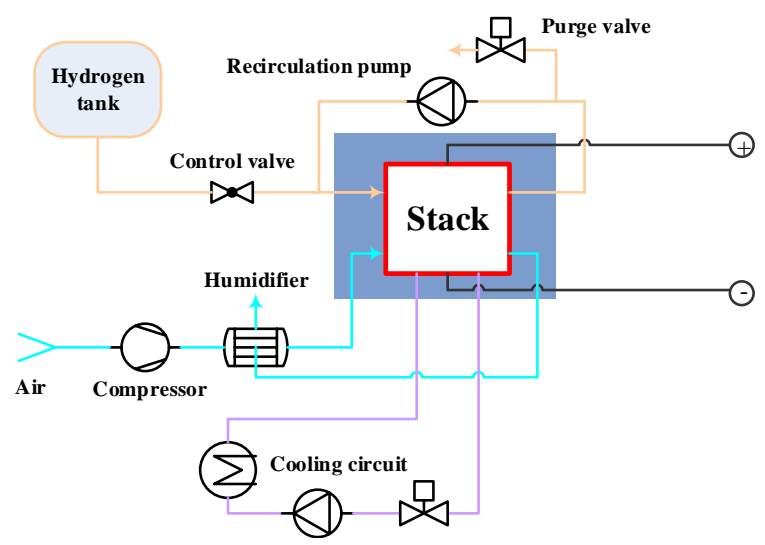

Fig. 3: Schematic of the PEMFCS [22].

[33], [43], oxidation of carbon support caused by fuel starvation at high or transient loading [44]-[47], production of surface oxides at very low loading [48]. It can be seen that the PEMFCS operating condition has a substantial influence on ECASA reduction. Extremum loads are very detrimental to the catalyst layer.

b) Membrane degradation [33]: fuel impurity, mechanical stress, and thermal stress lead to membrane degradation [44]-[46]. The former two are related to contaminants and congenital or assembly defects, respectively [44], [45]. They 


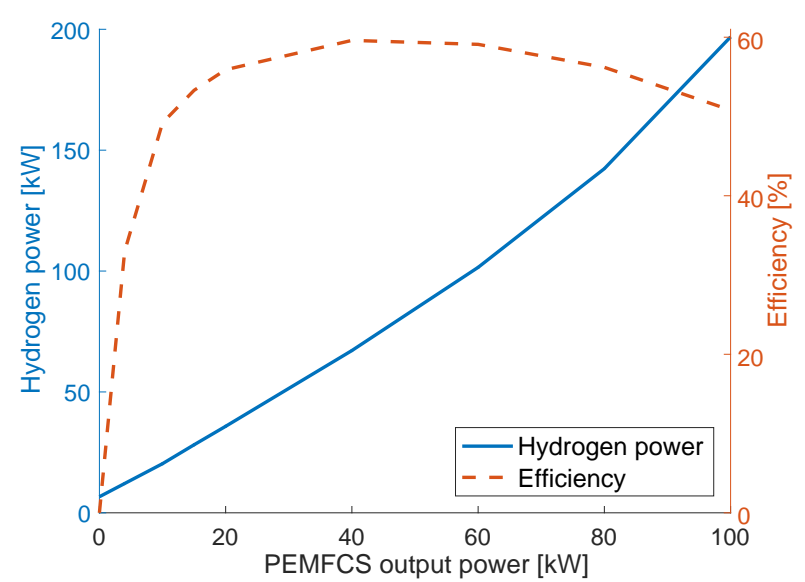

Fig. 4: Hydrogen consumption model of the PEMFCS.

are thus typically irrelevant to PEMFCS loading. However, thermal stress is dependent on the PEMFCS output power. Extensive heat at extremum loads may reduce the membrane protonic conductivity and incur membrane-drying-caused gas permeability [33], [44], [45].

c) Gas diffusion layer (GDL) degradation [33]: it has some overlapping aging mechanisms with the catalyst support. For example, fuel starvation at high or transient loading induces oxidation of carbon that is often exacerbated at high temperatures [33], [44], [45]. In addition, increased humidity at high loads may cause flooding [44], [49].

According to the foregoing descriptions [33], [44]-[49], the main MEA degradation mechanisms with respect to PEMFCS loading are summarized in Fig. 5. Since vehicular applications are invariably subject to drastically dynamic loading, it is of particular significance and practicality to carefully govern the PEMFCS loading (i.e., output power) to alleviate its performance degradation and increase the overall vehicular economy. It has been demonstrated in [32], [33], [40] that on/off loading has a predominately negative impact on the lifetime of PEMFCS, especially in heavy-duty vehicular applications. Therefore, as manipulated in [14], [22], [34], the bus PEMFCS is herein always on. We adopt a similar approach to [33], [40], so as to account for the effects of other loads. When the PEMFC output power $P_{f c s}$ is equal to or larger than $80 \%$ of the power rating, the voltage degradation rate per hour at high load is portrayed by $\gamma_{h i g h}$; when the PEMFC output power $P_{f c s}$ is lower than $20 \%$ of the power rating, the voltage degradation rate per hour at low load is denoted by $\gamma_{\text {low }}$; the voltage degradation rate per $\mathrm{kW}$ during transient load change is depicted by $\gamma_{c h g}$. The values of these rates used in this work are listed in Table II] As treated in [33], these sources of degradation are assumed to be mostly independent, and thus their effects can be summed up to embody the total voltage degradation.

\section{Battery Model}

1) Electrical Model: A 2000-cell lithium iron phosphate battery pack with the nominal energy capacity of $15.18 \mathrm{kWh}$ is employed as the energy storage unit of the hybrid powertrain,

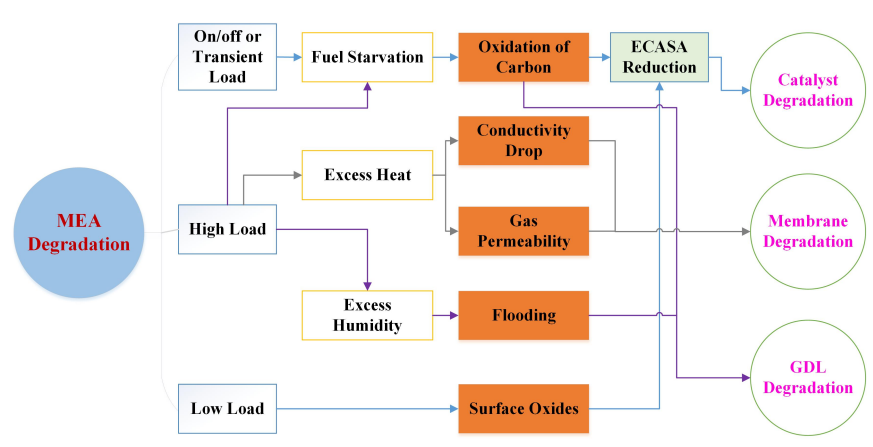

Fig. 5: Main MEA degradation mechanisms with respect to PEMFCS loading.

TABLE II. PEMFCS DEGRADATION RATE (CELL LEVEL).

\begin{tabular}{ll}
\hline \hline Load & Degradation rate \\
\hline${ }^{a}$ High load & $10.00 \mu \mathrm{V} / \mathrm{h}$ \\
${ }^{a}$ Low load & $8.662 \mu \mathrm{V} / \mathrm{h}$ \\
${ }^{b}$ Load change & $0.04185 \mu \mathrm{V} / \mathrm{kW}$ \\
\hline \hline
\end{tabular}

${ }^{a}$ Adopted from [40]; ${ }^{b}$ Adapted from [33] and [40].

whose configuration is illustrated in Fig. 6. Each battery cell is emulated by the internal resistance model as follows:

$$
V_{\text {cell }}(k)=u(k)-i(k) R
$$

where $V_{\text {cell }}, u, i$, and $R$ represent the terminal voltage, opencircuit voltage, current, and internal resistance of battery cell, respectively. Note that the open-circuit voltage $u$ is a monotonically increasing function of cell SOC, which is often provided by the manufacturer (see [50] for A123's ANR26650m1 used here). Given the terminal cell power $P_{\text {cell }}(k)=V_{\text {cell }}(k) i(k)$ and (3), we can obtain the following current equation:

$$
i(k)=\frac{u(k)-\sqrt{u^{2}(k)-4 R P_{\text {cell }}(k)}}{2 R}
$$

where $P_{\text {cell }}(k)=\frac{P_{\text {bat }}(k)}{n_{\text {all }}}=\frac{P_{\text {bat }}(k)}{n_{s} n_{p}}=\frac{P_{\text {bat }}(k)}{2000}$. And then the SOC dynamics can be delineated by

$$
\operatorname{soc}(k+1)=\operatorname{soc}(k)-\frac{i(k) \Delta t}{Q}
$$

where $s o c, Q$ and $\Delta t$ are the cell SOC, the nominal cell capacity, and the sampling interval, respectively. The following electrical constraints must be fulfilled when operating the hybrid powertrain:

$$
\begin{aligned}
i_{\min } \leq i(k) & \leq i_{\max } \\
s o c_{\min } \leq \operatorname{soc}(k) & \leq s o c_{\max } \\
\operatorname{soc}(0) & =\operatorname{soc}_{0}
\end{aligned}
$$

where $i_{\min }$ and $i_{\max }$ are the cell current bounds (maximum charge/discharge current); $s o c_{\min }$ and $s o c_{\max }$ are the SOC bounds, and $s o c_{0}$ is the initial SOC.

2) Health Model: A semi-empirical battery aging model developed in [51] is adopted in this paper to simulate the capacity loss of the battery cell. This model was already widely used for vehicular energy management [52], battery charging control [53], power-source sizing [34], [54], [55], 


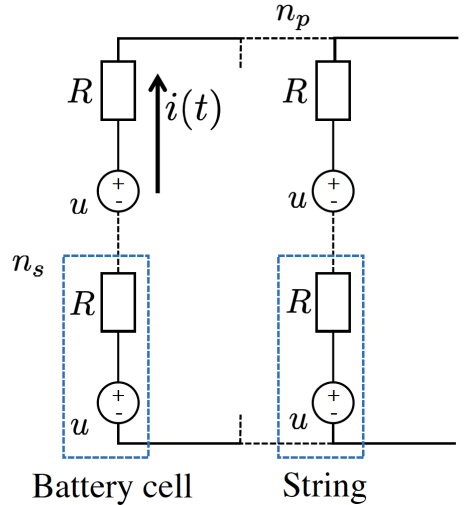

Fig. 6: Battery pack configuration [14].

TABLE III. PRE-EXPONENTIAL FACTOR AS A FUNCTION OF THE C-RATE [51].

\begin{tabular}{ccccc}
\hline \hline C-rate & 0.5 & 2 & 6 & 10 \\
\hline $\mathrm{M}$ & 31630 & 21681 & 12934 & 15512 \\
\hline \hline
\end{tabular}

etc. To ensure a completeness of model description, next, we brief this capacity loss model. More details are given in [51].

The cell capacity loss is characterized by the following equation [51]

$$
\Delta Q=M(c) \exp \left(\frac{-E_{a}(c)}{R_{c} T_{c}} A(c)^{z}\right)
$$

where $\Delta Q$ is the percentage of capacity loss in [\%], $c$ is the $\mathrm{C}$-rate, and $M$ is the pre-exponential factor as a function of the C-rate, as indicated in Table III] The ideal gas constant is $R_{c}(8.31 \mathrm{~J} / \mathrm{mol} \cdot \mathrm{K}), T_{c}$ is the lumped battery temperature in [K], and $A$ is the discharged ampere-hour (Ah) throughput. The activation energy $E_{a}$ in $[\mathrm{J} / \mathrm{mol}]$ and the power-law factor $z$ are determined by [51]

$$
\begin{aligned}
E_{a}(c) & =31700-370.3 c \\
z & =0.55 .
\end{aligned}
$$

When using (8) and Table III], 1C $(c=1)$ corresponds to $2 \mathrm{~A}$ [51], where a de-rated $2 \mathrm{Ah}$ was used to ease experimentation. $20 \%$ capacity loss is considered as the end-of-life (EOL) of an automotive battery, and the total discharged Ah throughput $A_{t o l}$ is, therefore, acquired by

$$
A_{t o l}\left(c, T_{c}\right)=\left[\frac{20}{M(c) \exp \left(\frac{-E_{a}(c)}{R_{c} T_{c}}\right)}\right]^{1 / z} .
$$

Then, the number of cycles until the battery EOL, $N$, is attained by [52]

$$
N\left(c, T_{c}\right)=\frac{3600 A_{t o l}\left(c, T_{c}\right)}{Q} .
$$

As a result, the State-of-Health ( $\mathrm{SOH})$ is defined below [52]:

$$
\operatorname{soh}(t)=1-\frac{\int_{0}^{t}|i(\tau)| d \tau}{2 N\left(c, T_{c}\right) Q}
$$

TABLE IV. MAIN ELECTRICAL SPECIFICATIONS OF THE BATTERY CELL.

\begin{tabular}{ll}
\hline \hline Parameter & Value \\
\hline${ }^{a}$ Internal resistance & $0.01 \mathrm{Ohm}$ \\
${ }^{a}$ Nominal capacity & $8280 \mathrm{As}$ \\
${ }^{b}$ Maximal charge current & $-35 \mathrm{~A}$ \\
${ }^{b}$ Maximal discharge current & $70 \mathrm{~A}$ \\
Maximal SOC & $75 \%$ \\
Minimal SOC & $55 \%$ \\
Initial SOC & $65 \%$ \\
Maximal SOH & $100 \%$ \\
Minimal SOH & $0 \%$ \\
Initial SOH & $100 \%$ \\
\hline \hline${ }^{a}$ Adopted from [50]; ${ }^{b}$ Adopted from [52].
\end{tabular}

The corresponding dynamic SOH model is thereby established as [52]

$$
\operatorname{soh}(k+1)=\operatorname{soh}(k)-\frac{|i(k)| \Delta t}{2 N\left(c, T_{c}\right) Q} .
$$

Based on the $\mathrm{SOH}$ model, the values of $\mathrm{N}$ and $\mathrm{SOH}$ decline rate at various temperatures and $\mathrm{C}$-rates can be easily calculated (e.g., see Fig. 15 in [55] with a C-rate with respect to the nominal capacity of $2.3 \mathrm{Ah}$ ). The following health constraints must be fulfilled when operating the hybrid powertrain:

$$
\begin{aligned}
\operatorname{soh}_{\text {min }} \leq & \operatorname{soh}(k) \leq \operatorname{soh}_{\text {max }} \\
\operatorname{soh}(0) & =\operatorname{soh}_{0}
\end{aligned}
$$

where $s o h_{\min }$ and $s o h_{\max }$ are the $\mathrm{SOH}$ bounds, and $s o h_{0}$ is the initial $\mathrm{SOH}$. The main electrical and $\mathrm{SOH}$ specifications of the battery are listed in Table IV

\section{MPC ENERGy MANAGEMENT Framework}

In this section, we mathematically formularize the predictive, cost-optimal power management strategy in an MPC framework.

\section{A. Objective function}

To minimize the total running cost of the bus over each prediction horizon, the objective function $J$ includes four terms, which is defined by

$$
J_{j}=C_{h, j}+C_{f c s, j}+C_{b a t, j}+D_{s o c, j}, j=0,1,2 \ldots
$$

where

1) $C_{h, j}$ is the hydrogen cost over the prediction horizon $j$, i.e.,

$$
C_{h, j}=\sum_{m=j}^{j+T_{h}-1} \beta_{h} P_{h}(m) \Delta t, j=0,1,2 \ldots
$$

with $T_{h}$ being the size of prediction/control horizon and $\beta_{h}$ the hydrogen price per Joule.

2) The PEMFCS degradation cost $C_{f c s, j}$ is computed by

$$
C_{f c s, j}=C_{\text {low }, j}+C_{\text {high }, j}+C_{c h g, j}, j=0,1,2 \ldots
$$

where $C_{l o w, j}$ is the degradation cost caused by low load, which is calculated by

$$
C_{\text {low }, j}=\frac{\gamma_{\text {low }} T_{\text {low }, j} M_{f c s}}{V_{f c s, e o l}}, j=0,1,2 \ldots
$$


with $T_{l o w, j}$ being the duration of low load in hour over the prediction horizon $j, V_{f c s, e o l}$ the voltage drop until the PEMFCS EOL (i.e., 10\% voltage decrease of fuel cell at rated current [40]), and $M_{f c s}$ the PEMFCS cost, i.e., $M_{f c s}=100 \beta_{f c s}$ where $\beta_{f c s}$ is the PEMFCS price per kW. Moreover, $C_{h i g h, j}$ is the degradation cost caused by high load, as defined by

$$
C_{h i g h, j}=\frac{\gamma_{h i g h} T_{h i g h, j} M_{f c s}}{V_{f c s, e o l}}, j=0,1,2 \ldots
$$

with $T_{h i g h, j}$ being the duration of high load in hour over the prediction horizon $j$. Then, $C_{c h g, j}$ is the degradation cost caused by load change, which is derived by

$$
C_{c h g, j}=\frac{\gamma_{c h g} M_{f c s} \sum_{m=j}^{j+T_{h}-2}\left|P_{f c s}(m+1)-P_{f c s}(m)\right|}{1000 n_{f c s} V_{f c s, e o l}}
$$

$j=0,1,2 \ldots$ with $n_{f c s}=1000$ being the number of fuel cells.

3) The battery degradation cost $C_{b a t, j}$ is calculated by

$$
C_{b a t, j}=M_{b a t}\left(\operatorname{soh}(j)-\operatorname{soh}\left(j+T_{h}\right)\right), j=0,1,2 \ldots
$$

where $M_{b a t}$ is the cost of the battery system, i.e., $M_{b a t}=$ $15.18 \beta_{\text {bat }}$ with $\beta_{\text {bat }}$ being the battery price per $\mathrm{kWh}$.

4) $D_{\text {soc, } j}$ is a deliberate penalty term to make the battery charge-sustaining as much as possible [56], i.e.,

$$
D_{s o c, j}=D_{p} \sum_{m=j}^{j+T_{h}}\left(\operatorname{soc}(m)-s o c_{0}\right)^{2}, j=0,1,2 \ldots
$$

with $D_{p}$ being a large, positive constant.

\section{B. Constraints}

Equations (1) and 2) enable us to only choose the PEMFCS output power $P_{f c s}$ as the optimization variable to reduce computational burden (the battery power $P_{b a t}$ can be invariably represented as a function of $\left.P_{f c s}\right)$. And then, the constraints of the optimal control problem consist of (5), (6), (12), (13), which can be described as functions of $P_{f c s}$, as well as the physical bounds on $P_{f c s}$,

$$
P_{f c s, \min } \leq P_{f c s}(k) \leq P_{f c s, \max }
$$

with $P_{f c s, \min }$ and $P_{f c s, \max }$ equal to 0 and 100000 , respectively.

\section{Framework formulation}

Given the objective function and constraints above, the cost minimization problem over the prediction/control horizon at the time step $j$ can be mathematically framed as follows:

$$
\begin{aligned}
& \min _{P_{f c s}(k), k=j, \ldots, j+T_{h}-1} J_{j}= C_{h, j}+C_{f c s, j} \\
&+C_{b a t, j}+D_{s o c, j} \\
& \text { s.t. } \forall k \in\left\{j, \ldots, j+T_{h}-1\right\}, q \in\left\{j, \ldots, j+T_{h}\right\}, \\
& \operatorname{soc}(k+1)= \operatorname{soc}(k)-\frac{i(k) \Delta t}{Q} \\
& i_{\min } \leq i(k) \leq i_{\max } \\
& \operatorname{soc}_{\min } \leq \operatorname{soc}(q) \leq \operatorname{soc}_{\max } \\
& \operatorname{soc}(0)=\operatorname{soc}_{0}
\end{aligned}
$$

TABLE V. BASELINE PRICES OF THE HYDROGEN, PEMFCS, AND BATTERY UNIT.

\begin{tabular}{ll}
\hline \hline Price & Value \\
\hline${ }^{a}$ Hydrogen & $4.00 \$ / \mathrm{kg}$ \\
${ }^{b}$ PEMFCS & $93.00 \$ / \mathrm{kW}$ \\
${ }^{c}$ Battery unit & $178.41 \$ / \mathrm{kWh}$ \\
\hline \hline
\end{tabular}

${ }^{a}$ Adopted from [60]; ${ }^{b}$ Adopted from [61] with medium-volume manufacturing of 10000 units/year; ${ }^{c}$ Adopted from [62].
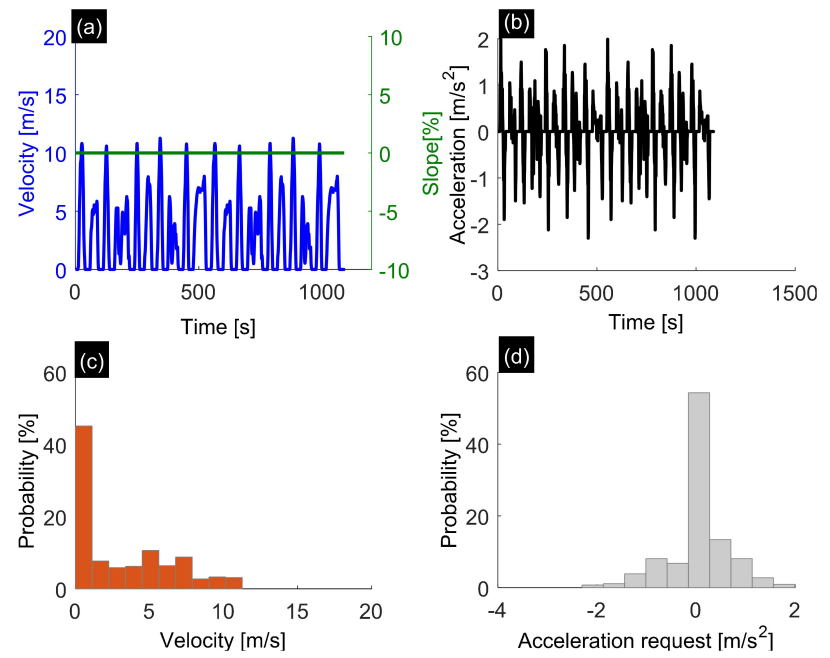

Fig. 7: MBC driving cycle [22]: (a) speed and slope, (b) acceleration, (c) speed distribution, and (d) acceleration distribution.

$$
\begin{aligned}
\operatorname{soh}(k+1) & =\operatorname{soh}(k)-\frac{|i(k)| \Delta t}{2 N\left(c, T_{c}\right) Q} \\
\operatorname{soh}_{\min } & \leq \operatorname{soh}_{(q)} \leq \operatorname{soh}_{\max } \\
\operatorname{soh}(0) & =\operatorname{soh}_{0} \\
P_{f c s, \min } & \leq P_{f c s}(k) \leq P_{f c s, \text { max }} .
\end{aligned}
$$

Note that the current $i$ in (23) is only an expression of $P_{f c s}$, with the consideration of (1), (2) and (4). We harness sequential quadratic programming (SQP) algorithm to solve the optimal control problem (23), as this algorithm has been corroborated to work well in a spectrum of MPC engineering applications [57]-[59]. For the solution over the current horizon $\left[P_{f c s}^{*}(j), \cdots, P_{f c s}^{*}\left(j+T_{h}-1\right)\right]$, only the first element $P_{f c s}^{*}(j)$ is applied to the hybrid powertrain to evolve the system dynamics, while the remaining elements are discarded. Such a manipulation is repeated at the next time step $k+1$ and is called the receding-horizon principle.

\section{RESUlts AND Discussions}

In this section, we present optimization results via running the aforementioned MPC energy management framework. The baseline prices of the hydrogen, PEMFCS, and battery unit are given in Table $\mathrm{V}$. As an example, the standard Manhattan bus cycle (MBC) from [22] is herein considered (see Fig. 7).

\section{A. Optimized cost and power split}

Given an exemplary prediction/control horizon $T_{h}=3$, equivalent to three seconds, the optimized cost outcome is 


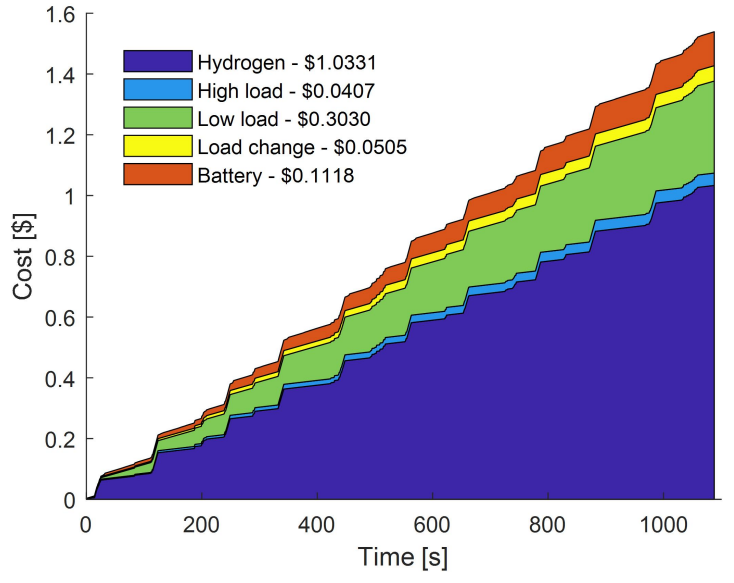

Fig. 8: Optimal cost result.

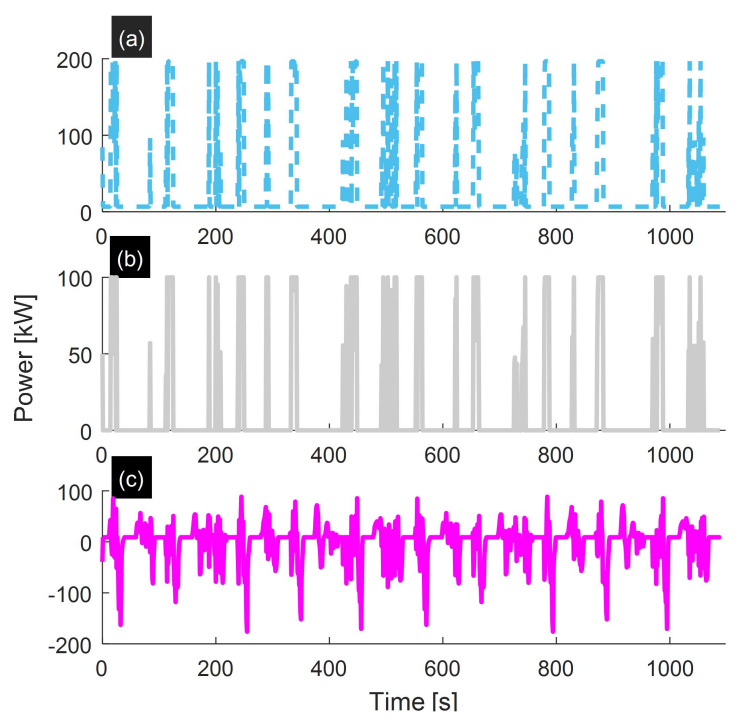

Fig. 9: Optimal power split: (a) hydrogen power, (b) PEMFCS power, and (c) battery power.

shown in Fig. 8. The total running cost in MBC is approximately $\$ 1.5390$, to which the hydrogen cost of $\$ 1.0331$ contributes most. The PEMFCS degradation cost of about $\$ 0.3941$ constitutes the second large expense, to which three sources, i.e., high load, low load, and load change, contribute. Clearly, the contribution of low load to the PEMFCS degradation is dominant. The battery degradation cost of $\$ 0.1118$ is smallest, compared to those of hydrogen and PEMFCS degradation.

The optimized power split between the PEMFCS and the battery pack is depicted in Fig. 9 and the corresponding motor electric power is presented in Fig. 10 It is clear that the PEMFCS largely operates at low load to mitigate its degradation, with the aid of battery power variances. The associated trajectories of battery SOC and SOH are illustrated in Fig. 11 . It can be found that the proposed MPC energy management solution works well to ensure the battery charge sustenance. The battery SOH decline is slight, less than $0.005 \%$.

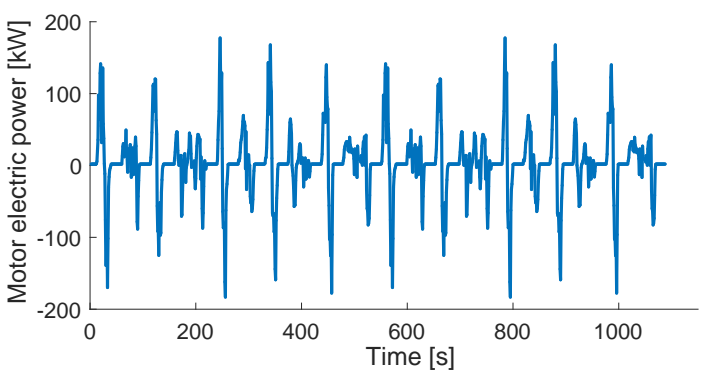

Fig. 10: Trajectory of the motor electric power.

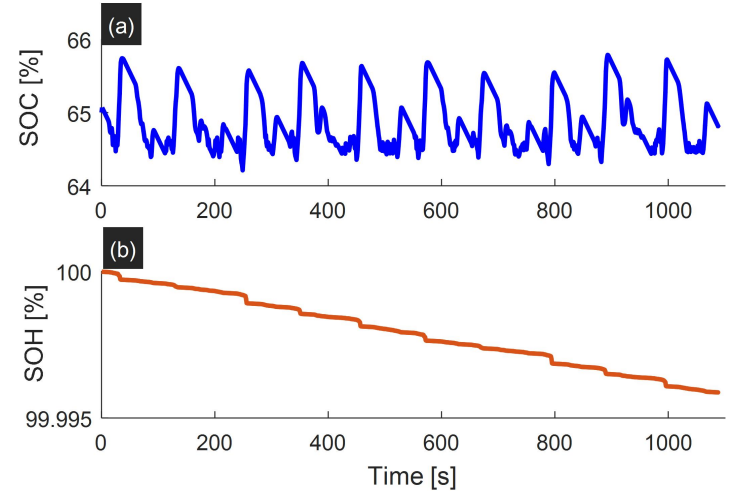

Fig. 11: Optimal battery states: (a) SOC and (b) SOH.

\section{B. Horizon effect}

In this subsection, we investigate how the size of the prediction/control horizon affects the optimization accuracy and computational burden. As shown in Fig. 12, the total running cost reduces, as the horizon size increases. The computational burden, however, becomes increasingly heavy, particularly when the size exceeds 10s. Therefore, the choice of the horizon size needs a balance between the optimality and computational efficiency for a specific case study. For example, as for lowcost energy controllers with limited computational capability, it is probably sensible to pick a relatively small horizon size, e.g., less than $5 \mathrm{~s}$, to assure real-time implementability. On the contrary, in the case of a computationally powerful controller, we most possibly prioritize the optimality over the computational load, so as to seek a large horizon size, e.g., greater than $9 \mathrm{~s}$.

\section{Effect of prediction uncertainty}

In the above discussion, we assume that the bus velocity trajectory in the prediction horizon is exactly known. This assumption is highly judicious, as bus routes are typically fixed, especially in city transit applications. With the development of vehicle-to-vehicle (V2V) and vehicle-to-infrastructure (V2I) communication, highly credible velocity predictors are expected even in the context of varying, complex routes. Vehicular velocity forecasting itself is a vast area of intensive studies, leading to a diversity of prediction methods. Please, for example, refer to [63], [64] for more related details. Since the main contributions and focus of this endeavor do not lie in velocity prediction, we straightforwardly evaluate how 


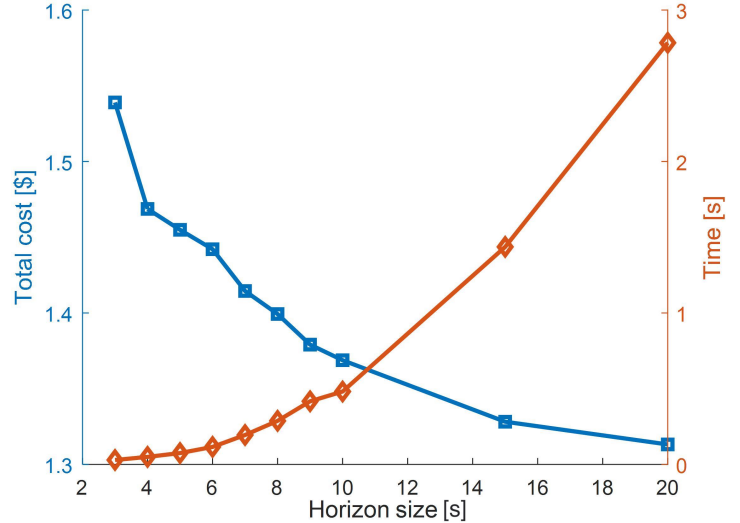

Fig. 12: Optimal cost and average calculation time per step as functions of horizon size (a $3.5 \mathrm{GHz}$ CPU with $32 \mathrm{~GB}$ RAM was used).

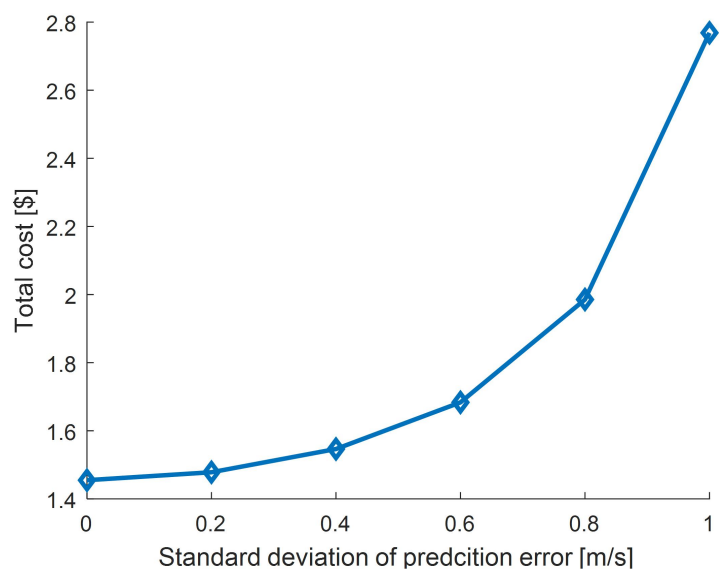

Fig. 13: Optimal cost versus prediction error.

potential prediction uncertainty influences the optimal cost by adding artificial Gaussian prediction errors of different standard deviations to the MBC data. To maintain physical viability, the contaminated negative velocity is set to zero. Take a prediction/control horizon $T_{h}=5$ as an example. The associated result is illustrated in Fig. 13 . It is clear that the optimized cost increases with augmented prediction error. When the standard deviation of the error equals to 1 , the total cost virtually doubles, in contrast to the benchmark with perfect velocity. Hence, it is of great importance to obtain sufficiently precise velocity evolution, from a perspective of saving vehicular running cost.

It is worth mentioning that, in the case of imperfect velocity forecasting, as the prediction horizon increases, the prediction uncertainty most probably increases. Such an error increase may somewhat offset the optimality gain obtained by increasing the prediction horizon. As such, the performance improvement of the predictive controller resulting from the horizon increase may saturate. As a result, we cannot arbitrarily augment the prediction horizon, which should be decided by a nontrivial, comprehensive consideration of the prediction uncertainty, optimality gain, and computational load.

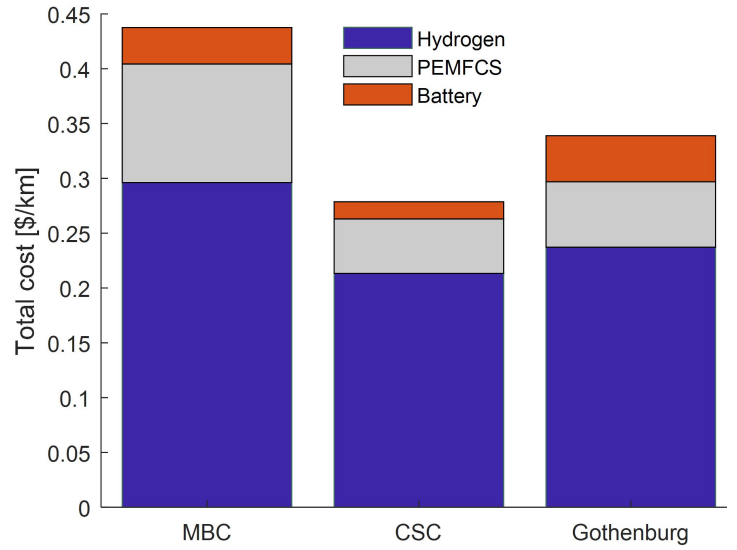

Fig. 14: Comparative result among MBC, CSC, and Gothenburg cycle.

\section{DRIVING AND PRICING IMPACT}

In this section, the influence of driving and pricing scenarios on the optimization outcome is elucidated.

\section{A. Driving Impact}

In addition to MBC, we consider another two bus cycles, i.e., the standard city suburban cycle (CSC) and a realistic Gothenburg city cycle with slope knowledge (see Figs. 8 and 9 of [22]). In this way, how the driving pattern affects the optimal cost can be unveiled. Given $T_{h}=5$, the total costs under the three driving cycles in $\$ / \mathrm{km}$ are compared in Fig. 14 It is evident that the harshest MBC induces the highest expense, i.e., about $\$ 0.44 / \mathrm{km}$. In $\mathrm{MBC}$, the prime mover, PEMFCS, experiences the most dynamic loads, giving rise to higher hydrogen cost and PEMFCS degradation. In the other extremum, the smoothest CSC leads to the lowest expense, i.e., about $\$ 0.28 / \mathrm{km}$ (36.4\% reduction versus MBC). In CSC, the hydrogen cost, PEMFCS cost, and battery cost are all lowest in the three cycles. The total expense in the Gothenburg cycle is in between MBC and CSC, i.e., $\$ 0.34 / \mathrm{km}(22.7 \%$ reduction versus $\mathrm{MBC}$ ). In this cycle, the battery degradation is, however, largest, because the hilly driving requires more frequent utilization of the battery system.

\section{B. Pricing Impact}

We examine the pricing impact on the optimization result, through considering price evolutions of hydrogen, PEMFCS, and battery in the most recent three years (from 2017 to 2019). Table $\mathrm{V}$ ]is used as the baseline prices in 2017 . The annual price increase of hydrogen is assumed to be $20 \%$, due to increasingly serious energy shortage. The PEMFCS price decrease is from [61] (about 5\% annually), while that of the battery is from [62] (about 11\% annually), due to economies of scale and growing maturity of design/manufacturing technologies. The price evolutions are shown in Fig. 15

The optimization results are plotted in Fig. 16 It is pronounced that the optimal cost gradually increases from 2017 to 2019. For example, in MBC, the increases in 2018 and 2019 reach $11.27 \%$ and $26.02 \%$, respectively, with respect to the 


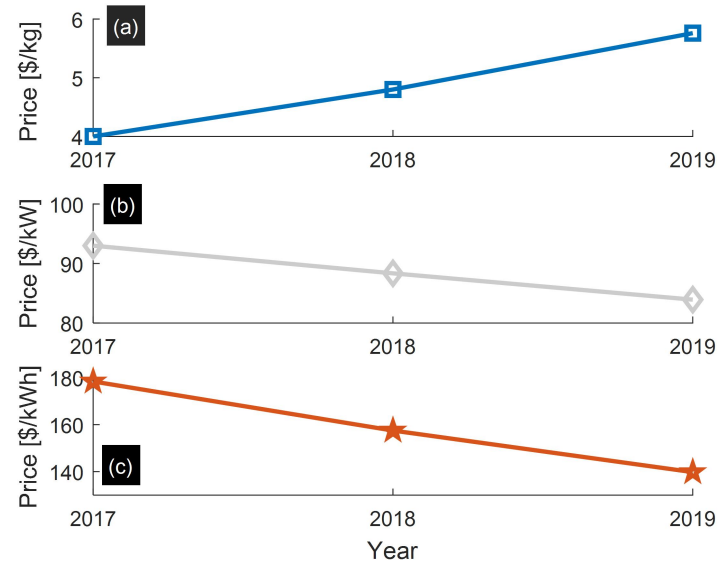

Fig. 15: Price evolutions of hydrogen (a), PEMFCS (b), and battery (c) in the three years.

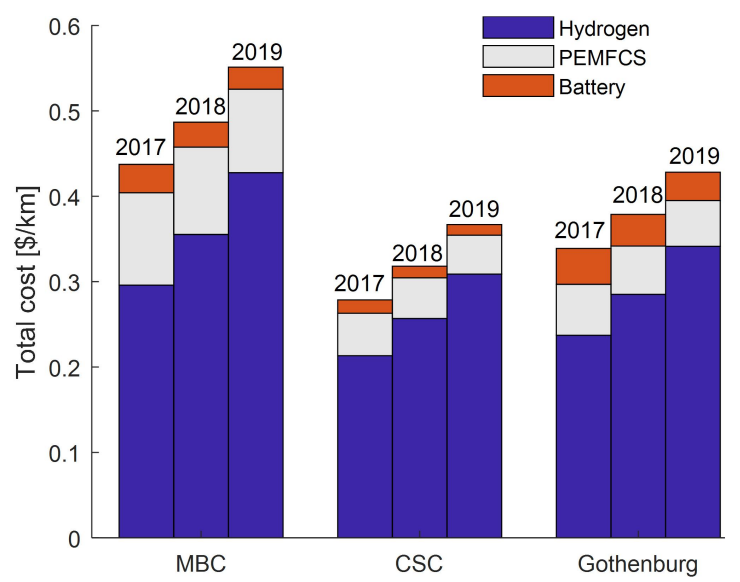

Fig. 16: Optimization results in the three years (from 2017 to 2019).

baseline case in 2017 . The reason is the noticeably augmented hydrogen cost, due to its price increase. From the results in all the three cycles, we can see that the costs of PEMFCS and battery degradation are only slightly reduced.

In the future, more sophisticated models can be established to predict price evolutions of hydrogen, PEMFCS, and battery. The obtained results will then be incorporated into the proposed energy management framework to investigate their effects.

\section{CONCLUSIONS}

This paper devises a cost-optimal, predictive energy management strategy for hybrid powertrains, which is cognizant of the lifetime of both fuel cell and battery systems. In the strategy, the total running expense of a PEMFCS/battery hybrid electric bus, inclusive of hydrogen cost and costs of fuel cell and battery degradation, is minimized in an MPC setting. The effectiveness and computational efficiency of this strategy are validated via numerous simulation campaigns, and the effects of prediction horizon and prediction uncertainties are assessed. Furthermore, how driving and pricing scenarios impact the optimization results are investigated.
The key findings include the following five points:

1) The proposed method presents an alternative idea for developing cost-optimal energy management strategies of fuel cell/battery hybrid electric vehicles.

2) How to pick an appropriate horizon size entails a tradeoff between the optimality and computational efficiency, according to controller properties. As the horizon size becomes larger, the total running cost reduces, whereas the computational load increases.

3) Velocity prediction uncertainties thwart the reduction of total running cost. When the standard deviation of uncertainty equals to 1 , the total cost of the bus increases by nearly $100 \%$

4) Driving patterns significantly influences the optimized cost. The highest expense, i.e., about $\$ 0.44 / \mathrm{km}$, occurs in the harshest MBC. As the driving becomes smoother, we can accomplish $22.7 \%$ and $36.4 \%$ cost reductions in the Gothenburg and CSC cycles, respectively.

5) The potential price changes of hydrogen, PEMFCS, and battery will increase the optimized cost, due to predominantly augmented hydrogen cost. In MBC, the cost increases in 2018 and 2019 are $11.27 \%$ and $26.02 \%$, respectively, versus the baseline case in 2017 . The cost decreases of PEMFCS and battery degradation are very slight.

\section{REFERENCES}

[1] W. Su, H. Rahimi-Eichi, W. Zeng, and M.-Y. Chow, "A survey on the electrification of transportation in a smart grid environment," IEEE Trans. Ind. Informat., vol. 8, no. 1, pp. 1-10, Feb. 2012.

[2] T. Hua, R. Ahluwalia, L. Eudy, G. Singer, B. Jermer, N. Asselin-Miller, S. Wessel, T. Patterson, and J. Marcinkoski, "Status of hydrogen fuel cell electric buses worldwide," J. Power Sources, vol. 269, no. 3, pp. 975-993, Dec. 2014.

[3] H. S. Das, C. W. Tan, and A. H. M. Yatim, "Fuel cell hybrid electric vehicles: A review on power conditioning units and topologies," Renew. Sustain. Energy Rev., vol. 76, pp. 268-291, Sep. 2017.

[4] L. Hu, Y. Zhong, W. Hao, B. Moghimi, J. Huang, X. Zhang, and R. Du, "Optimal route algorithm considering traffic light and energy consumption," IEEE Access, vol. 6, pp. 59695-59704, Sep. 2018.

[5] U. Eberle, B. Müller, and R. V. Helmolt, "Fuel cell electric vehicles and hydrogen infrastructure: Status 2012," Energy Environ. Sci., vol. 5, no. 10, pp. 8780-8798, 2012

[6] Y. Hames, K. Kaya, E. Baltacioglu, and A. Turksoy, "Analysis of the control strategies for fuel saving in the hydrogen fuel cell vehicles," Int. J. Hydrogen Energy, vol. 43, no. 23, pp. 10810-10 821, 2018.

[7] S. Onori, L. Serrao, and G. Rizzoni, Hybrid Electric Vehicles-Energy Management Strategies. London: Springer, 2016.

[8] M. F. M. Sabri, K. A. Danapalasingam, and M. F. Rahmat, "A review on hybrid electric vehicles architecture and energy management strategies," Renew. Sustain. Energy Rev., vol. 53, pp. 1433-1442, Jan. 2016.

[9] C. M. Martinez, X. Hu, D. Cao, E. Velenis, B. Gao, and M. Wellers, "Energy management in plug-in hybrid electric vehicles: Recent progress and a connected vehicles perspective," IEEE Trans. Veh. Technol., vol. 66, no. 6, pp. 4534-4549, Jun. 2017.

[10] T. Hofman, M. Steinbuch, R. V. Druten, and A. Serrarens, "Rule-based energy management strategies for hybrid vehicles," Int. J. Electric \& Hybrid Veh., vol. 1, no. 1, pp. 71-94, 2007.

[11] J. Gao, F. Sun, H. He, G. G. Zhu, and E. G. Strangas, "A comparative study of supervisory control strategies for a series hybrid electric vehicle," in Asia-Pacific Power Energy Eng. Conf., Wuhan, China, Mar. 2009, pp. 1-7.

[12] N. S. Lee, G. M. Jeong, and H. S. Ahn, "Improvement of fuel economy using fuzzy logic-based power distribution control strategy for a FCHEV," in Int. Conf. Comput. Intellig. Secur., Guangzhou, China, Nov. 2006, pp. 891-894. 
[13] B. D. Jager, T. V. Keulen, and J. Kessels, Optimal Control of Hybrid Vehicles. Springer London, 2013.

[14] X. Hu, J. Jiang, B. Egardt, and D. Cao, "Advanced power-source integration in hybrid electric vehicles: Multicriteria optimization approach," IEEE Trans. Ind. Electron., vol. 62, no. 12, pp. 7847-7858, Dec. 2015.

[15] I. L. Sarioglu, B. Czapnik, E. Bostanci, O. P. Klein, H. Schröder, and F. Küçükay, "Optimum design of a fuel-cell powertrain based on multiple design criteria," J. Power Sources, vol. 266, no. 10, pp. 7-21, Nov. 2014.

[16] Z. Dimitrova and F. Maréchal, "Techno-economic design of hybrid electric vehicles using multi objective optimization techniques," Energy, vol. 91, pp. 630-644, Nov. 2015

[17] C.-C. Lin, H. Peng, J. Grizzle, and J.-M. Kang, "Power management strategy for a parallel hybrid electric truck," IEEE Trans. Control Syst. Technol., vol. 11, no. 6, pp. 839-849, Nov. 2004.

[18] M. J. Kim and H. Peng, "Power management and design optimization of fuel cell/battery hybrid vehicles," J. Power Sources, vol. 165, no. 2, pp. 819-832, Mar. 2007.

[19] L. Xu, M. Ouyang, J. Li, and F. Yang, "Dynamic programming algorithm for minimizing operating cost of a PEM fuel cell vehicle," in IEEE International Symposium on Industrial Electronics (ISIE), Hangzhou, China, 2012, pp. 1490-1495.

[20] N. Murgovski, L. Johannesson, J. Sjöberg, and E. Bo, "Component sizing of a plug-in hybrid electric powertrain via convex optimization," Mechatronics, vol. 22, no. 1, pp. 106-120, Feb. 2012.

[21] B. Egardt, N. Murgovski, M. Pourabdollah, and L. Johannesson Mardh, "Electromobility studies based on convex optimization: Design and control issues regarding vehicle electrification," IEEE Control Syst. Mag., vol. 34, no. 2, pp. 32-49, Apr. 2014.

[22] X. Hu, N. Murgovski, L. M. Johannesson, and E. Bo, "Optimal dimensioning and power management of a fuel cell/battery hybrid bus via convex programming," IEEE/ASME Trans. Mechatron., vol. 20, no. 1, pp. 457-468, Feb. 2015.

[23] P. Rodatz, G. Paganelli, A. Sciarretta, and L. Guzzella, "Optimal power management of an experimental fuel cell/supercapacitor-powered hybrid vehicle," Control Eng. Prac., vol. 13, no. 1, pp. 41-53, Jan. 2005.

[24] C. Musardo, G. Rizzoni, Y. Guezennec, and B. Staccia, "A-ECMS: An adaptive algorithm for hybrid electric vehicle energy management," European J. Control, vol. 11, no. 4-5, pp. 509-524, 2005.

[25] N. Kim, S. Cha, and H. Peng, "Optimal control of hybrid electric vehicles based on Pontryagin's minimum principle," IEEE Trans. Control Syst. Technol., vol. 19, no. 5, pp. 1279-1287, Sep. 2011.

[26] C. H. Zheng, N. W. Kim, and S. W. Cha, "Optimal control in the power management of fuel cell hybrid vehicles," Int. J. Hydrogen Energy, vol. 37, no. 1, pp. 655-663, Jan. 2012

[27] J. Luna, S. Jemei, N. Yousfi-Steiner, A. Husar, M. Serra, and D. Hissel, "Nonlinear predictive control for durability enhancement and efficiency improvement in a fuel cell power system," J. Power Sources, vol. 328, pp. $250-261$, Oct. 2016.

[28] Y. Huang, H. Wang, A. Khajepour, H. He, and J. Ji, "Model predictive control power management strategies for HEVs: A review," J. Power Sources, vol. 341, pp. 91-106, 2017.

[29] J. P. Ribau, C. M. Silva, and J. M. C. Sousa, "Efficiency, cost and life cycle $\mathrm{CO}_{2}$ optimization of fuel cell hybrid and plug-in hybrid urban buses," Appl. Energy, vol. 129, no. 129, pp. 320-335, Sep. 2014.

[30] B. Geng, J. K. Mills, and D. Sun, "Two-stage energy management control of fuel cell plug-in hybrid electric vehicles considering fuel cell longevity," IEEE Trans. Veh. Technol., vol. 61, no. 2, pp. 498-508, Feb. 2012.

[31] C. H. Zheng, G. Q. Xu, Y. I. Park, W. S. Lim, and S. W. Cha, "Prolonging fuel cell stack lifetime based on Pontryagin's minimum principle in fuel cell hybrid vehicles and its economic influence evaluation," J. Power Sources, vol. 248, pp. 533-544, Feb. 2014.

[32] T. Fletcher, R. H. Thring, M. Watkinson, and I. Staffell, "Comparison of fuel consumption and fuel cell degradation using an optimised controller," ECS Transactions, vol. 71, no. 1, pp. 85-97, 2016.

[33] T. Fletcher, R. H. Thring, and M. Watkinson, "An energy management strategy to concurrently optimise fuel consumption and PEM fuel cell lifetime in a hybrid vehicle," Int. J. Hydrogen Energy, vol. 41, no. 46 , pp. $21503-21515$, Dec. 2016.

[34] X. Hu, L. Johannesson, N. Murgovski, and B. Egardt, "Longevityconscious dimensioning and power management of the hybrid energy storage system in a fuel cell hybrid electric bus," Appl. Energy, vol. 137, pp. 913-924, Jan. 2015.

[35] L. Xu, C. D. Mueller, J. Li, M. Ouyang, and Z. Hu, "Multi-objective component sizing based on optimal energy management strategy of fuel cell electric vehicles," Appl. Energy, vol. 157, pp. 664-674, Nov. 2015.
[36] Z. Song, H. Hofmann, J. Li, J. Hou, X. Zhang, and M. Ouyang, "The optimization of a hybrid energy storage system at subzero temperatures: Energy management strategy design and battery heating requirement analysis," Appl. energy, vol. 159, pp. 576-588, Dec. 2015.

[37] Z. Song, H. Hofmann, J. Li, X. Han, and M. Ouyang, "Optimization for a hybrid energy storage system in electric vehicles using dynamic programing approach," Appl. Energy, vol. 139, pp. 151-162, Feb. 2015.

[38] L. Guzzella and A. Sciarretta, Vehicle Propulsion Systems: Introduction to Modeling and Optimization, 3rd Edition. Berlin: Springer, 2013.

[39] L. Guzzella and A. Amstutz, "CAE tools for quasi-static modeling and optimization of hybrid powertrains," IEEE Trans. Veh. Technol., vol. 57, no. 6, pp. 1762-1769, Nov. 1999.

[40] H. Chen, P. Pei, and M. Song, "Lifetime prediction and the economic lifetime of proton exchange membrane fuel cells," Appl. Energy, vol. 142, pp. 154-163, Mar. 2015.

[41] J. T. Pukrushpan, A. G. Stefanopoulou, and H. Peng, Control of fuel cell power systems : principles, modeling, analysis, and feedback design. Springer, 2004

[42] K. B. Wipke, M. R. Cuddy, and S. D. Burch, "ADVISOR 2.1: a user-friendly advanced powertrain simulation using a combined backward/forward approach,” IEEE Trans. Veh. Technol., vol. 48, no. 6, pp. 1751-1761, Nov. 1999.

[43] J. Wu, X. Z. Yuan, J. J. Martin, H. Wang, D. Yang, J. Qiao, and J. Ma, "Proton exchange membrane fuel cell degradation under close to opencircuit conditions: Part i: In situ diagnosis," J. Power Sources, vol. 195, no. 4, pp. 1171-1176, Feb. 2010.

[44] L. Placca and R. Kouta, "Fault tree analysis for PEM fuel cell degradation process modelling," Int. J. Hydrogen Energy, vol. 36, no. 19, pp. 12393-12 405, Sep. 2011.

[45] X. Z. Yuan, H. Li, S. Zhang, J. Martin, and H. Wang, "A review of polymer electrolyte membrane fuel cell durability test protocols," $J$. Power Sources, vol. 196, no. 22, pp. 9107-9116, Nov. 2011.

[46] S. Zhang, X. Yuan, H. Wang, W. Mérida, H. Zhu, J. Shen, S. Wu, and J. Zhang, "A review of accelerated stress tests of MEA durability in PEM fuel cells," Int. J. Hydrogen Energy, vol. 34, no. 1, pp. 388-404, Jan. 2009.

[47] S. J. Bae, S. J. Kim, J. I. Park, W. P. Chan, J. H. Lee, I. Song, N. Lee, K. B. Kim, and J. Y. Park, "Lifetime prediction of a polymer electrolyte membrane fuel cell via an accelerated startup-shutdown cycle test," Int. J. Hydrogen Energy, vol. 37, no. 12, pp. 9775-9781, Jun. 2012.

[48] V. B. Avakov, V. A. Bogdanovskaya, A. V. Kapustin, O. V. Korchagin, A. V. Kuzov, I. K. Landgraf, M. M. Stankevich, and M. R. Tarasevich, "Lifetime prediction for the hydrogen-air fuel cells," Russian J Electrochem., vol. 51, no. 6, pp. 570-586, Jun. 2015.

[49] W. Schmittinger and A. Vahidi, "A review of the main parameters influencing long-term performance and durability of PEM fuel cells," J. Power Sources, vol. 180, no. 1, pp. 1-14, May. 2008.

[50] A123 Systems, "High power lithium ion ANR26650M1," May. 2011. [Online]. Available: http://www.robotcombat.com/products/images/bp_ configs/pdf//ANR26650M1.pdf

[51] J. Wang, P. Liu, J. Hicks-Garner, E. Sherman, S. Soukiazian, M. Verbrugge, H. Tataria, J. Musser, and P. Finamore, "Cycle-life model for graphite-LiFePO 4 cells," J Power Sources, vol. 196, no. 8, pp. 3942 3948, Apr. 2011.

[52] S. Ebbesen, P. Elbert, and L. Guzzella, "Battery state-of-health perceptive energy management for hybrid electric vehicles," IEEE Trans. Veh. Technol., vol. 61, no. 7, pp. 2893-2900, Sep. 2012.

[53] H. Perez, X. Hu, S. Dey, and S. Moura, "Optimal charging of Li-ion batteries with coupled electro-thermal-aging dynamics," IEEE Trans. Veh. Technol., vol. 66, no. 7, pp. 7761-7770, Sep. 2017.

[54] L. Johannesson, N. Murgovski, S. Ebbesen, B. Egardt, E. Gelso, and J. Hellgren, "Including a battery state of health model in the HEV component sizing and optimal control problem," in IFAC Symposium on Advances in Automotive Control, Sep. 2013, pp. 398-403.

[55] X. Hu, Y. Zou, and Y. Yang, "Greener plug-in hybrid electric vehicles incorporating renewable energy and rapid system optimization," Energy, vol. 111, pp. 971-980, Sep. 2016.

[56] J. Unger, M. Kozek, and S. Jakubek, "Nonlinear model predictive energy management controller with load and cycle prediction for non-road HEV," Control Eng. Prac., vol. 36, pp. 120-132, Mar. 2015.

[57] M. J. Tenny, S. J. Wright, and J. B. Rawlings, "Nonlinear model predictive control via feasibility-perturbed sequential quadratic programming," Comput. Opt. Appl., vol. 28, no. 1, pp. 87-121, Apr. 2004.

[58] R. Ghaemi, J. Sun, and I. V. Kolmanovsky, "An integrated perturbation analysis and sequential quadratic programming approach for model predictive control," Automatica, vol. 45, no. 10, pp. 2412-2418, Oct. 2009. 
[59] T. Amraee, A. M. Ranjbar, and R. Feuillet, "Adaptive under-voltage load shedding scheme using model predictive control," Electric Power Systems Research, vol. 81, no. 7, pp. 1507-1513, Jul. 2011.

[60] J. Eichman, A. Townsend, and M. Melaina, "Economic assessment of hydrogen technologies participating in california electricity markets," National Renewable Energy Laboratory, Colorado, USA, Tech. Rep. NREL/TP-5400-65856, Feb. 2016.

[61] "Fuel cell system cost-2016," DOE Hydrogen and Fuel Cells Program Record, U. S. Dept. of Energy, Washington, DC, USA, Record No. 16020, Sep. 2016.

[62] N. Kittner, F. Lill, and D. M. Kammen, "Energy storage deployment and innovation for the clean energy transition," Nature Energy, vol. 2, no. 9:17125, 2017.

[63] C. Sun, X. Hu, S. J. Moura, and F. Sun, "Velocity predictors for predictive energy management in hybrid electric vehicles," IEEE Trans. Control Syst. Technol., vol. 23, no. 3, pp. 1197-1204, May. 2015.

[64] R. Wang and S. M. Lukic, "Review of driving conditions prediction and driving style recognition based control algorithms for hybrid electric vehicles," in Veh. Power Propulsion Conf., Chicago, USA, Sep. 2011, pp. 1-7.

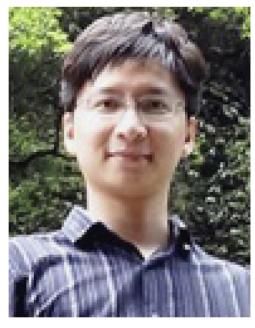

Xiaosong Hu (SM'16) received the Ph.D. degree in Automotive Engineering from Beijing Institute of Technology, China, in 2012.

He did scientific research and completed the Ph.D. dissertation in Automotive Research Center at the University of Michigan, Ann Arbor, USA, between 2010 and 2012. He is currently a professor at the State Key Laboratory of Mechanical Transmissions and at the Department of Automotive Engineering, Chongqing University, Chongqing, China. He was a postdoctoral researcher at the Department of Civil and Environmental Engineering, University of California, Berkeley, USA, between 2014 and 2015, as well as at the Swedish Hybrid Vehicle Center and the Department of Signals and Systems at Chalmers University of Technology, Gothenburg, Sweden, between 2012 and 2014. He was also a visiting postdoctoral researcher in the Institute for Dynamic systems and Control at Swiss Federal Institute of Technology (ETH), Zurich, Switzerland, in 2014. His research interests include modeling and control of alternative powertrains and energy storage systems.

Dr. Hu has been a recipient of several prestigious awards/honors, including Emerging Sustainability Leaders Award in 2016, EU Marie Currie Fellowship in 2015, ASME DSCD Energy Systems Best Paper Award in 2015, and Beijing Best Ph.D. Dissertation Award in 2013.

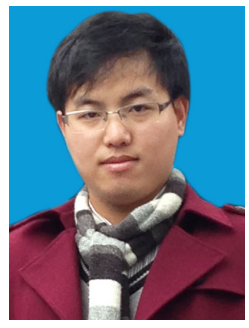

Changfu Zou (M'16) received the B.E. degree in automotive engineering from the Beijing Institute of Technology, Beijing, China, and the Ph.D. degree from the Department of Mechanical Engineering, The University of Melbourne, Parkville, Victoria, Australia, in 2011 and 2017, respectively.

He was a Postdoctoral Researcher and is currently an Assistant Professor with Automatic Control Group at the Department of Electrical Engineering, Chalmers University of Technology, Gothenburg, Sweden. He was a visiting student researcher with the Energy, Controls \& Applications Lab, University of California, Berkeley, USA, from 2015 to 2016. His research interests include modelling and control of energy storage systems, electrified vehicles and transport systems.

Dr. Zou was Guest Editor for IEEE Transactions on Industrial Informatics and IET Intelligent Transport Systems, and the recipient of Excellent Graduate Award of Beijing, Melbourne Research Scholarship, Scholarship of National ICT Australia, and Engineering \& IT Melbourne Abroad Travel Scholarships.

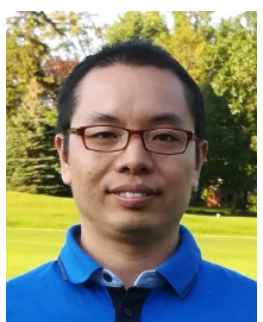

Xiaolin Tang received the B.S. degree in mechanics engineering and the M.S. degree in vehicle engineering from Chongqing University, Chongqing, China, in 2006 and 2009, respectively, and the Ph.D. degree in mechanical engineering from Shanghai Jiao Tong University, Shanghai, China, in 2015.

$\mathrm{He}$ is currently an Associate Professor with the State Key Laboratory of Mechanical Transmissions and with the Department of Automotive Engineering, Chongqing University. His research interests include hybrid electric vehicles, vehicle dynamics, noise and vibration, and transmission control.

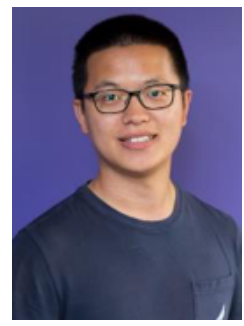

Teng Liu (M'18) received the B.S. degree in mathematics from Beijing Institute of Technology, Beijing, China, 2011. He received his Ph.D. degree in automotive engineering from Beijing Institute of Technology (BIT), Beijing, in 2017. His Ph.D. dissertation, under the supervision of Prof. Fengchun Sun, was entitled "Reinforcement learning-based energy management for hybrid electric vehicles." He worked as a research fellow in Vehicle Intelligence Pioneers Ltd for one year. Now, he is a member of IEEE VTS, IEEE ITS, IEEE IES, IEEE TEC, and

\section{IEEE/CAA.}

Dr. Liu is now a postdoctoral fellow at the Department of Mechanical and Mechatronics Engineering, University of Waterloo, Ontario N2L3G1, Canada. Dr. Liu has more than 8 years' research and working experience in renewable vehicle and connected autonomous vehicle. His current research focuses on reinforcement learning (RL)-based energy management in hybrid electric vehicles, RL-based decision making for autonomous vehicles, and CPSSbased parallel driving. He has published over 40 SCI papers and 15 conference papers in these areas. He received the Merit Student of Beijing in 2011, the Teli Xu Scholarship (Highest Honor) of Beijing Institute of Technology in 2015, "Top 10" in 2018 IEEE VTS Motor Vehicle Challenge and sole outstanding winner in 2018 ABB Intelligent Technology Competition. Dr. Liu is a workshop co-chair in 2018 IEEE Intelligent Vehicles Symposium (IV 2018) and has been reviewers in multiple SCI journals, selectively including IEEE Trans. Industrial Electronics, IEEE Trans. on Intelligent Vehicles, IEEE Trans. Intelligent Transportation Systems, IEEE Transactions on Systems, Man, and Cybernetics: Systems, IEEE Transactions on Industrial Informatics, Advances in Mechanical Engineering.

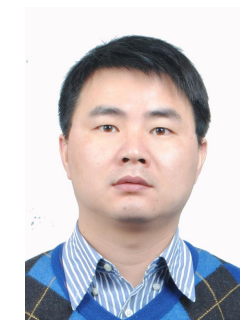

Lin Hu received the Ph.D. degree from the College of Mechanical and Vehicle Engineering, Hunan University, China, in 2008

$\mathrm{He}$ is currently an Associate Professor and Associate Dean of the College of Automotive and Mechanical Engineering, Changsha University of Science and Technology, China. His areas of expertise include intelligent vehicle and vehicle and traffic safety.

Dr. Hu was the winner of Science Fund For Distinguished Young Scholars of the Hunan Province, and the second Prize for Progress in Science and Technology of the Hunan Province of China. 